\title{
Temporal Existence and Temporal Location
}

\section{Introduction}

In everyday discourse, we frequently use the tensed verb 'to exist' as a means to predicate temporal location. Thus when, in ordinary circumstances, we utter the sentence 'There existed no man-made weather events until after the Industrial Revolution', we are naturally taken to say no more than that there were no manmade weather events located at any time before the Industrial Revolution. We are not, thereby, already making any controversial ontological claim, viz. that some of the things that are presently something were nothing before the Industrial Revolution.

In philosophical contexts, by contrast, we do use the tensed verb 'to exist' in order to speak, precisely, about what is presently something but in the past, was nothing. There are accordingly two distinct notions readily expressed by the tensed verb 'to exist' that it is of crucial importance not to conflate: the notion of being located at the present time, and the notion of belonging to the domain of quantification at the present time.

Nevertheless, conflation of these two notions abounds in the contemporary debate about presentism - or so we shall undertake to demonstrate. Before this diagnosis can be appreciated as correct, however, it behoves us to make the distinction between these two notions, and their applications, as clear as possible.

\section{Locational uses of 'to exist'}

Ordinary language philosophy as a programme is no longer en vogue, perhaps for good reason. But sometimes an exercise in ordinary language philosophy can still provide a successful first step in devising a cure against philosophical confusions. This, we submit, is the case with regard to a certain strand in the current debate 
about temporal existence - with important consequences for the proper assessment of presentism.

In ordinary discourse, we frequently use the tensed verb 'to exist' in ways exemplified by utterances of sentences such as

(1) There existed no tomatoes in Europe in the 1350s

It seems natural to refuse taking (1) to imply that, at any time in the 1350s and anywhere in Europe, the sentence 'There exist no tomatoes' was true. For, in the 1350s, tomatoes did exist in Mexico and so 'There exist no tomatoes' was after all false back then, whether in Europe or anywhere else. At best, (1) should be taken to imply that the sentence 'There exist no tomatoes in Europe' was true throughout the 1350s.

We might want to further explain this rather natural assessment by saying that what exists does not vary with geographical location. But if we do say this, what do we mean when we say that no tomatoes existed in Europe at the time? If what exists does not vary with geographical location, we cannot paraphrase the sentence 'There exist no tomatoes in Europe' by 'In Europe, there exist no tomatoes' where 'In Europe' functions like an operator as in 'In Europe, it frequently rains'. For, if unlike the weather, what exists does not vary with geographical location, such an operator is an idle wheel whenever it is used to prefix a clause about what exists; and so, since tomatoes did exist somewhere on the planet in the 1350s, 'In Europe, there exist no tomatoes' was false at the time. Our paraphrase would not then preserve truth in the 1350s.

The example reveals that we often use the tensed verb 'to exist' in order to indicate what is, and what is not, to be found somewhere at a given time, and hence to indicate what does, and what does not, occupy a given spatial location at a given time. Thus it does not take much reflection to realise that an acceptable paraphrase of the sentence 'There existed no tomatoes in Europe in the 1350s' would be 'No tomatoes were to be found in Europe throughout the 1350s'. Accordingly, the observation that the vernacular 'There exist no tomatoes in Europe' was true in the 
1350s should be taken to imply no more and no less than that so was the sentence 'No tomatoes are to be found in Europe'.

When in an ordinary conversation, to which an utterance of 'There existed no tomatoes in Europe in the 1350s' may as well belong, we uttered the sentence

(2) There existed no broccoli in $800 \mathrm{BC}$

we would likewise be naturally understood as committing ourselves to no more, and no less, than that broccoli was nowhere to be found in 800 BC. Similarly, in ordinary conversations in which we utter 'Dodos no longer exist', we are naturally understood to commit ourselves to nothing other than that dodos are no longer to be found anywhere.

Dodos and vegetables are so-called continuants. But we also use the tensed verb 'to exist' in application to other kinds of things in time; and as we shall see, we do so with comparable intentions. For example, we may on occasion utter one of the following sentences:

(3) There existed no man-made weather events until after the Industrial Revolution

(4) By $500 \mathrm{AD}$ the Western Roman Empire no longer existed

In ordinary contexts, utterances of (3) are naturally understood as saying no more, and no less, than that no man-made weather events occurred until after the Industrial Revolution; and ordinary utterances of (4) are naturally understood as saying nothing other than that the Western Roman Empire lasted no longer than some time before $500 \mathrm{AD}$. Weather events like empires have a temporal extension; and for them to occur during, or to last throughout, a certain stretch of time is for their temporal extension to include that stretch of time.

Continuants like dodos and broccoli, and temporally extended things of the kinds exemplified by weather events and empires, have a spatial extension and so 
a spatial location. But we sometimes speak as if not all things in time could sometimes be found somewhere, i.e. at some spatial location. To the extent that we can quantify over fictional characters at all, it is indeed plausible to hold that such characters are not in any way spatially located, and yet are in time (cf. Thomasson 1999 for a philosophical defence of that view). For instance, one might wish to affirm

Sherlock Holmes did not yet exist in 1550

On a natural understanding of (5), it conveys that Sherlock Holmes had not yet been created in 1550 .

All these ways of using the tensed verb 'to exist' have something in common, or so we now suggest. For, there is a sense in which all such uses of 'to exist' serve to locate things at times. This is most straightforwardly so in the case of temporally extended things like weather events and empires. For, such things are precisely located at the times included in their temporal extension, i.e. the times during which they occur or throughout which they last; and we saw that sentences like (3) and (4) convey information about the latter.

But even in the case of spatially extended continuants we may say that such continuants are located at times, if only indirectly, viz. that they are located at precisely those times at which some episode of their histories, or lives, is located; and any episode of the history, or life, of a spatially extended continuant has both a spatial and a temporal extension. Accordingly, while it remains true that to say of broccoli that it exists but did not exist in $800 \mathrm{BC}$ is to say that it is somewhere to be found at the present time but at no time in $800 \mathrm{BC}$, it can also be maintained that broccoli is to be found somewhere at a given time just in case some episode of the history of broccoli is located at that time. If some such episode is located at a given time, then, indirectly, so is broccoli. ${ }^{1}$

\footnotetext{
${ }^{1}$ Damiano Costa has recently advocated a theory of persistence through time - transcendentism, as he calls it - according to which for a continuant (Costa uses the term 'object') to exist at a time is for it to participate in certain events that are located at that time (Costa 2017). This theory is similar to the view put forward here. However, unlike Costa we do not offer a theory of temporal
} 
Similarly, to say that Sherlock Holmes exists but did not yet exist in 1550 is to say that this fictional character was created only after 1550 and remains in the public imagination until the present time; and there is then a sense, albeit an indirect one, in which Sherlock Holmes is located at the times at which its creation and imaginings take place.

Let us use 'to be present' as being short for 'is located at the present time', in the semi-technical sense just characterised in which even continuants, and creations of the human mind such as fictional characters, can be located at the present time (cf. also Cameron 2017: 127-29). What it is for a time to be the present time should be no mystery - at least there is a perfectly plain and familiar usage of the phrase 'the present time' in ordinary language according to which, at any given time $t$, that phrase denotes $t$, and according to which, correspondingly, a time $t$ is present whenever $t$ is the referent of 'now'. Accordingly, just as the phrase 'the present time' refers to a different time at different times, something may at some time be present, in the sense defined, without being present at another. ${ }^{2}$ Accordingly, the claim is that the tensed verb 'to exist' is frequently used in ways in which its use could, without significant loss, be paraphrased away by using 'to be present' instead.

\section{Ontological uses of 'to exist'}

Nothing of the foregoing shows that there are no other uses of the verb 'to exist' that resist such a paraphrase. Philosophers are indeed mostly interested in uses of that verb according to which to exist just is to be something - i.e. to be in the range of the existential quantifier. While most philosophers agree that what exists in this sense of 'exists' does not vary with geographical location, many are attracted to the idea that what exists in this sense still varies with temporal location. But then,

existence, but make the more modest claim that ordinary usage licences a construal of 'exists at $t$ ' as 'is located at $t$ ' even when applied to continuants.

${ }^{2}$ There arguably is also a use of 'the present time' according to which it serves as temporally rigid designator of the time of utterance, in just the same way the indexical 'now' does. This is evidently not the use we intend here. Rather, we here understand 'the present time' to function in such a way that 'Always, for all times $t$, at $t, t$ is the present time' comes out true. 
many others regard the idea of such temporal variation as deeply flawed. Accordingly, while it can universally be agreed, on mere empirical grounds, that broccoli was not located at any time in 800 BC, in the sense of temporal location introduced before, to say of broccoli that it was nothing in $800 \mathrm{BC}$ is highly controversial, as is the claim that sometimes in the past there were dodos that are nothing today.

On certain ontological views - viz. those Timothy Williamson labels 'permanentist' - always everything always exists (Williamson 2013). Just as 'rains' does not cease to be tensed when embedded in 'It always rains in Oslo', 'exists' does not cease to be tensed when embedded in the sentence articulating the permanentists' key thesis. Indeed, according to standard tense-logic, 'Always, $x$ exists' is definitionally equivalent to '(Always in the past, $x$ exists) \& $x$ exists \& (Always in the future, $x$ exists)'; and here the second conjunct is rather evidently intended to be in the present tense. Accordingly, the permanentists' key thesis is formulated using 'exists' in a tensed way; and yet, that thesis expressly rules out that what exists varies with time. ${ }^{3}$ It would therefore be mistaken to suggest that whenever philosophers use 'to exist' in a tensed way, they eo ipso subscribe to the claim that there is such variation. ${ }^{4}$

\footnotetext{
${ }^{3}$ Endorsement of the permanentist thesis does not yet commit one to the claim that the tensed notion of existence, used to formulate that thesis, is basic.

${ }^{4}$ Deasy (2017) insists that the quantifiers of predicate logic 'are tenseless' - in which case so would be 'exists' in the second sense here identified in which it is equivalent to 'is something'. Deasy's sole argument for this contention is that if ' $\exists x \operatorname{Dodo}(x)$ ' were tensed, ' $\mathrm{P} \exists x \operatorname{Dodo}(x)$ ' would have to be equivalent either to ' $\mathrm{PN} \exists x \operatorname{Dodo}(x)$ ' or to ' $\mathrm{PS} \exists x \operatorname{Dodo}(x)$ ', which it is decidedly not (where ' $\mathrm{P}$ ' is 'Sometimes in the past', ' $\mathrm{N}$ ' is 'Now', and ' $\mathrm{S}$ ' is 'Sometimes'). Given that 'Now' is temporally rigid, i.e. always takes us back to the time of utterance, the subjunctive is plain false: 'P(It rains in Oslo)' is neither tense-logically equivalent to 'PN(It rains in Oslo)' nor to 'PS(It rains in Oslo)'; and yet who would want to deny that 'It rains in Oslo' is tensed? Despite his insistence that quantification is tenseless, Deasy nonetheless goes on to consider transientism as a serious contender, where transientism is the following thesis: $\mathrm{S} \exists x \mathrm{P} \neg \exists y(y=x) \& \mathrm{~S} \exists x \mathrm{~F} \neg \exists y(y=$ $x$ ) (with ' $F$ ' being short for 'Sometimes in the future'). Deasy offers the following informal gloss on this thesis: 'As time passes, some things begin to be, and some things cease to be'. Yet, if quantification really is tenseless, then relative to any assignment to the variable ' $x$ ', if ' $\neg \exists y(y=$ $x$ )' is true at one time of evaluation it is true at any time of evaluation; and it evidently cannot be that sometimes, ' $\exists x \neg \exists y(y=x)$ ' holds. Accordingly, to the extent that transientism is at all coherent, Deasy is forced to deny that temporal operators shift the time of evaluation for the clause they embed. This goes against the standard conception of the significance of such operators. Deasy indeed contemplates an alternative view, labelled 'locator', according to which such operators 'are implicit quantifiers over instants of time which restrict the explicit individual
} 
If the permanentist thesis is correct, i.e. always everything always exists, then always, for all $x$ and all times $t, x$ exists at $t$. For, quite generally, 'Always, $\varphi$ ' entails 'For all times $t$, at $t, \varphi$ '. Thus, in particular, according to permanentism, Caesar always exists, and hence, Caesar exists at the present time. Ross Cameron suggests that, given this latter implication of permanentism, neither B-theorists nor proponents of the so-called Moving Spotlight Theory of time should accept the permanentist thesis. He goes on to argue that proponents of either theory should instead accept that, always, Caesar is 'in the domain of the absolutely unrestricted quantifier' (Cameron 2017: 111n). However, this is precisely what 'Caesar always exists', to the extent that it is derivable from the permanentist thesis, means. On the alternative reading of the sentence, according to which it means that Caesar is always located at what then is the present time, the sentence cannot be derived from that thesis. For, permanentism is clearly not intended as a thesis about temporal location. Accordingly, Cameron's recommendation is quite pointless.

Thus permanentists do not claim, or imply, that always everything is always present in the sense of 'present' previously identified (i.e. located at what then is the present time). For instance, their view is not already refuted by the fact that back in $800 \mathrm{BC}$, broccoli was nowhere to be found and so was not located at any time in 800 BC. Similarly, if a report on the 2012 CERN experiment includes the sentence

(6) The Higgs boson existed only for the briefest of moments

we do not take this report to refute the permanentists' key thesis. Rather, (6) is best understood as making a claim about the Higgs boson's temporal location; and permanentism is compatible with the observation that some things - like, for instance, bosons - are only ever temporally located during short periods of time.

quantifiers $(\forall, \exists)$ in their scope to things located at the relevant instant'. But read in this way, the thesis of transientism can no longer be glossed in the manner Deasy suggests: no longer (not yet) being located at the present time does not entail no longer (not yet) being something. (In fact, Deasy discusses locator merely in the context of the non-transientist B-theory; but this observation evidently does nothing to alleviate the problem.) 
Consequently, when permanentists affirm the sentence 'Always everything always exists', they do not use the present-tensed 'exists' as being equivalent to 'is both presently something and located at the present time'. For, otherwise empirical truths about broccoli, or Higgs bosons, would already refute their central claim.

Quite generally, it would be mistaken to suggest that whenever philosophers use the verb 'to exist' in a tensed way - as the case may be, by adding the qualification 'at $t$ ', for a given time $t$ - they use it to inter alia indicate temporal location. ${ }^{5}$

Permanentists deny that presently being something entails being located at the present time. But then, so should everyone else. This is not yet to rule out that always everything is located at what then is the present time. To say that always everything located at what then is the present time - as presentists do - is to make a substantive ontological claim, and not to articulate a conceptual entailment. Even presentists should be ready to acknowledge this (contrary to what Cameron at places suggests; Cameron 2017: 136).

Temporaryists deny the permanentists' key thesis, and so commit to the claim that sometimes something sometimes does not exist (Williamson 2013). In the light of the foregoing considerations, this amounts to the claim that sometimes something sometimes is nothing - and decidedly not to the claim that sometimes something sometimes fails to be located at what then is the present time. For, as explained, the latter claim, but not the former, is already vindicated empirically by the fact that in $800 \mathrm{BC}$ broccoli was nowhere to be found; and the ontological debate between permanentists and temporaryists is not decided on empirical grounds - or at least not on empirical grounds concerning broccoli.

\footnotetext{
${ }^{5}$ Torrengo (2012: 126-27) would seem to disagree when he suggests that tensed notions of existence not only 'contain implicit reference to the time of utterance', but furthermore 'seem to require reference to the temporal location of the entities to which we apply' them. Introducing an allegedly tenseless notion of 'simple existence' that contains no such reference, he nonetheless allows for temporal variation in that notion's range of application (i.e. the domain of quantification). Accordingly, claims about what exists simpliciter are after all tensed, on his view, in that they can vary in truth-value over time. To stabilise this combination of thoughts, Torrengo draws a somewhat artificial distinction between the tensedness of claims attributing simple existence and the tensedness of the notion of simple existence itself (ibid.). We see no reason to follow Torrengo here. The notion of what exists simpliciter - i.e. the notion of being in the range of the existential quantifier - that figures in tensed claims sensitive to tense-logical embedding, is itself tensed. Yet, applications of the notion do not - pace Torrengo - attribute any temporal location to the things to which it is applied.
} 
Is every temporaryist bound to subscribe to the presentist claim that always everything is whenever it is something located at the present time? If 'is something' has a tensed reading - as both permanentists and temporaryists assume - and if, on this reading, 'is something' does not entail 'is located at the present time' - then it is clear that there is no such commitment. Indeed, according to the Growing Block Theory of time, always something comes into existence that was nothing before - and so is not always something; and yet, on that same view, never is there anything that ceases to exist - and hence, always everything is always in the future going to be something. If proponents of this theory subscribed to the claim that always everything is whenever it is something also located at the present time, they would have to deny, absurdly, that dodos are extinct; and their view would have been refuted by the CERN experiment in 2012. But it is evident that the growing block theory of time is no more jeopardised by that experiment, or the extinction of dodos for that matter, than permanentism.

Whenever something spatially extended like a vegetable first comes into existence, if anything ever does, it is at that time to be found somewhere. Accordingly, assuming that they know enough about broccoli, proponents of the growing block theory of time will be committed to saying that broccoli is something but was nothing in $800 \mathrm{BC}$. For, broccoli was not yet to be found anywhere in $800 \mathrm{BC}$ or at any earlier time, and so was not located at any time in $800 \mathrm{BC}$; and broccoli is to be found somewhere today, from which it follows that it is located at the present time. It might therefore be tempting to conflate their commitment to

(7) Broccoli is presently something, but was nothing in $800 \mathrm{BC}$

with their commitment to

(8) Broccoli is presently to be found somewhere, but was nowhere to be found in $800 \mathrm{BC}$ 
But even if proponents of the growing block theory of time incur both these commitments, these commitments are still distinct. Their conflation leads to disaster. If the growing blocker's affirmation of (7) were mistakenly thought to reduce to her commitment to (8), her opposition to permanentism would be obscured from view. If the growing blocker's affirmation of (8) were mistakenly thought to reduce to her commitment to (7), it would become almost irresistible to interpret her commitment to (9) as a commitment to an outright contradiction:

(9) Dodos are presently something, but are not to be found anywhere at present

It is one thing to say that always everything will forever continue to exist - where 'exist' is equivalent to 'be something' - and quite another to say that always everything that is present will forever continue to be present - in the sense of 'present' characterised earlier in which dodos are present only when they are somewhere to be found. While everyone should deny the latter, growing blockers and permanentists alike accept, while presentists are bound to reject, the former. Similarly, it is one thing to say that always something exists that did not do so at any earlier moment - where 'exists' is again equivalent to 'is something' - and quite another to say that always something is present that was not present at any earlier moment. While everyone might accept the latter, permanentists - unlike presentists and growing blockers - are bound to reject the former.

\section{Conflations of the two types of use in recent work on presentism}

The conceptual distinction between present existence as presently being something, and present existence as being present, should by now be clear enough, if it was unclear before. It is the distinction between the notion of presently being within the range of the existential quantifier, and the notion of being located at the present time. Both these notions are tensed. Their being tensed does not make them equivalent.

The distinction between these two notions is also independent from any commitment to the ineradicability of tense in metaphysical reasoning. It can 
without problem be respected by eternalists who go beyond permanentism and deny that there is any factual variation at all along the temporal dimension. Eternalists can nonetheless still distinguish between two readings of ' $x$ exists at the present time’. On one reading, it is equivalent to ' $\exists y(y=x)$ '; and the only difference to their temporaryist opponents is that eternalists take the latter to have its truthvalue permanently. On another reading, ' $x$ exists at the present time' is equivalent to ' $x$ is located at $t$ ' whenever ' $t$ ' co-refers with 'now' ${ }^{6}$ Since for eternalists, the qualification 'at the present time' is idle on the first reading, it is unsurprising that most eternalists prefer to use ' $x$ exists at the present time' in its second reading, which is analogous to David Lewis' use of ' $x$ exists at the actual world'.

For all its clarity, however, the distinction tends to be obfuscated in many recent publications in the philosophy of time. For example, in a 2005 paper titled 'The Presentist's Dilemma', as well as in a follow-up publication from 2013, Ulrich Meyer considers whether the following is a faithful rendition of presentism's key thesis:

$$
\text { Nothing exists now that is not present }
$$

He thinks (10) will not do because '[t]o exist now and to be present are the very same thing' and concludes that '[s]ince the presentist clearly meant to advance a substantial thesis, it thus seems safe to conclude that [10] is not what he had in mind' (Meyer 2005: 214; see also Meyer 2013 and Tallant 2014: 480-81).

Deasy (2017) rightly points out that, given the indexical nature of 'now', 'exists now' and 'is present' behave differently under tense-logical embedding and hence cannot, after all, mean the same thing. However, Meyer may more charitably be understood as advancing the claim that 'exists at the present time' and 'is present'

\footnotetext{
${ }^{6}$ Eternalists take the latter claim to likewise have its truth-value eternally; temporaryists will disagree only on assumption that 'is located at' is existence-entailing, which it may well not be. 7 We here use the existential quantifier as unrelativised, so that for temporaryists and permanentists alike, whenever ' $\exists y(y=x)$ ' is true, it is true simpliciter. Even then, there is the option to introduce a time-relative existential quantifier in addition, thereby allowing for statements of the form ' $\exists_{t} y(y=x)$ ', where the latter is intended to be equivalent to ' $\exists y(y=x \& y$ is located at $t$ )'. This option in no way affects our discussion.
} 
mean the same thing, where 'the present time' unlike the indexical 'now' is not temporally rigid. While this may salvage Meyer's claim from Deasy’s refutation, making it one's basis for interpreting (10) is nonetheless a highly questionable move.

Meyer is not explicit what he takes being present to amount to; but we can catch a glimpse of what he means by looking at what he has to say about Caesar: 'Caesar does not exist now; he died on the Ides of March in 44 BC' and so 'is not present' (ibid.). Uncontroversially, if Caesar - the person, not his bodily remains - were located at the present time, he would be alive, and vice versa. Hence, if being dead implies not being present, then in order for Caesar to be present, it must be the case that he is located at the present time. Trivially, if Caesar were located at the present time, he would be present. According to Meyer, then, 'Caesar exists at the present time' is equivalent to 'Caesar is located at the present time'. As we saw, we often do use 'to exist' in this sense; and if (10) is read in this way, it indeed proves trivial.

But presentists qua temporaryists do not have this sense of 'to exist' in mind when advancing their thesis - inasmuch as permanentism is not refuted by bosons - but rather the sense of 'to exist' in which it is equivalent to 'is presently something'. On this alternative reading, (10) would be equivalent to

\section{(11) Presently nothing fails to be located at the present time}

As a formulation of presentism's key thesis, (11) of course proves too strong: not every presentist needs to be a nominalist, say, and reject the existence of numbers. But (11) could be suitably hedged, so as to restrict the range of quantification to things in time; and then (11) might no longer be too strong for the purpose (cf. Cameron 2017: 127).

However, Meyer ignores this alternative reading of (10) altogether - as does $\mathrm{M}$. Joshua Mozersky (2011: 123). Both authors would seem to presuppose, mistakenly as we have argued, that if 'exists' is tensed, it is bound to attribute a temporal location, viz. being located at the present time. 
Meyer instead goes on to discuss a fundamentally different formulation of presentism's key thesis, in which 'exists at the present time' in (10) is replaced by 'exists sometimes' (i.e. 'exists at some time or other'):

(12) Nothing exists sometimes that is not present

Meyer thinks (12) is 'obviously false' (see also Stoneham 2009; Mozersky 2011: 123; Tallant 2014: 481). There is independent reason to regard the latter diagnosis as mistaken: for, if (11) holds, then a fortiori there is nothing that satisfies ' $x$ exists at some time or other' but fails to satisfy ' $x$ is present' (Crisp 2004a; Sider 2006: 76, 85-86; Correia and Rosenkranz 2015; Deasy 2017: section 4). But this is not our present concern. What matters is that Meyer does not even consider (11) an option - which would after all be a most natural thing to do, were one to reflect on the aforementioned distinction.

Similarly, Mozersky is led to invoke a tenseless notion of existence, i.e. that of falling in the domain of a tenseless quantifier. According to Mozersky, presentists had better endorse:

(13) Only entities that exist now can satisfy the (temporally unrestricted, i.e. tenseless) existential quantifier

where 'exist now' is again construed in the way Meyer understands it, viz. as being equivalent to 'located at the present time'. Yet, if being in the range of the existential quantifier is a tenseless affair, then what is not in its range today won't be in that range tomorrow either. Accordingly, if (13), on Meyer's understanding of it, is true today, then tomorrow, tomorrow's breakfast will not be in that range, because tomorrow, tomorrow's breakfast will not have been located at any time today. The presentists' key thesis is supposed to hold always, if it holds at all (Sider 1999: 326; Deasy 2017). But then, tomorrow, (13) will be true, only if tomorrow, everything in the range of the existential quantifier will already have been located at some time today. Presentists (like anyone else, for that matter) are thus well- 
advised to refuse Mozersky's offering; and they have no need for it either, since (11), which uses a tensed quantifier, is neither trivially true nor obviously false.

Another illustration of the failure to fully appreciate the ambiguity of 'exists' is Tom Stoneham's paper 'Time and Truth: The Presentism-Eternalism Debate'. After initially characterising presentism as 'the view that only the present is real, that the future has not happened yet and that the past has irrecoverably departed', Stoneham goes on to say that the 'presentist believes that our ontology [...] should only include what exists right now, i.e. at the time we draw up the list [of what there is]' (Stoneham 2009: 201-202). He then considers whether the following is a good rendition of what presentists wish to say

(14) What there is only includes what exists now

Setting aside concerns about things outside time - such as, e.g., numbers - (14) is a serious contender for expressing presentism's key thesis only provided that 'exists now' is here construed as being equivalent to 'is located at the present time' (Zimmerman 1998: 209-10). In that case, (14) is equivalent to

(15) What there is only includes what is located at the present time

which is itself equivalent to (11) above. But this is precisely not how Stoneham construes 'exists now' (unlike, as we saw, Meyer and Mozersky). For, he thinks that once the present tense of 'is' is taken to heart - and 'what there is' is equivalent to 'what there is now' - we end up with a claim that is analytic (ibid.; cf. also Lombard 2010: 54-55). Again, failure to see that (15) is available is most naturally attributed to a failure to see the aforementioned distinction.

The debate between Thomas Crisp and Peter Ludlow about the proper formulation of presentism, and the conceptual resources needed for the purpose, presupposes that the following is not a good candidate:

(16) Only present things exist at present 
According to Crisp and Ludlow, (16) is trivial (Crisp 2004a: 16; Ludlow 2004: 22; see also Crisp 2004b; Lombard 1999: 254; Deng 2018: 794). 'For, what is a “present thing”', Crisp asks, 'but a thing that exists at present?' (ibid.). Crisp goes on to argue that the following is a better candidate:

(17) For every $x, x$ is a present thing

where the quantifier is restricted so as to range 'over the domain of all things in time' (Crisp 2004a: 18).

However, if a present thing is nothing 'but a thing that exists at present' - where here 'exists at present' is equivalent to 'is presently something' - then both permanentists and growing blockers can accept (17) (see Williamson 2013; Correia and Rosenkranz 2015). By contrast, if a present thing is understood to be a thing located at the present time, (17) will be unavailable to the presentist's opponents - just as Crisp intends. But then, note that on that very same interpretation, (16) is no longer trivial and will be rejected by permanentists and growing blockers alike. So, either commitment to (17) does not distinguish presentists from their opponents - viz. on its first reading - or else it indeed does, but then, in retrospect, there was no reason to suggest (17) as a replacement for (16) in the first place - viz. on its second reading. Accordingly, on either reading of (17), replacing (16) by (17) is an unhelpful manoeuvre.

In Crisp's case, as in Meyer's case, the prejudice would seem to be that if ' $x$ exists' is present-tensed, ' $x$ exists' entails ' $x$ is located at the present time'. It is ultimately for this reason that (10) and (16) are considered trivial. Crisp and Meyer should then also say that permanentism is falsified by facts about broccoli. This is evidently mistaken. Given how many commentators still take Crisp's trivialitychallenge seriously, the underlying confusion seems wide-spread (see, e.g., Miller 2013: 348-51; Ingram and Tallant 2018; Deng 2018: 794).

In Stoneham's case, by contrast, the prejudice would seem to be that presentists cannot help themselves to tensed uses of ' $x$ exists' according to which ' $x$ exists' 
does entail ' $x$ is located at the present time'. It is for this reason that (15) does not even come into view as a reading of Stoneham's initial offering, i.e. (14). But then Stoneham should also say that a defence of permanentism requires refutation of 'There existed no tomatoes in Europe in the 1350s', which shows that something is amiss.

\section{Conclusion}

We conclude that sensitivity to the distinction between the tensed notion of being something and the tensed notion of being located at the present time serves as a good antidote to confusions in debates about time and existence, and saves us the trouble of going through unnecessary epicycles. Both notions are frequently expressed using the tensed verb 'to exist', making it systematically ambiguous. It is a commendable strategy to avoid using that verb altogether in these contexts and to use quantification and a location-predicate instead. 


\section{References}

Cameron, R. 2017: 'On Characterizing the Presentism/Externalism and Actualism/Possibilism Debates', Analytic Philosophy 57, 110-40

Correia, F. and Rosenkranz, S. 2015: 'Presentism without Presentness', Thought 4, 19-27

Costa, D. 2017: 'The Transcendentist Theory of Persistence', The Journal of Philosophy 114, 57-75

Crisp, T. M. 2004a: ‘On Presentism and Triviality’, in Zimmerman (2004), 15-20

Crisp, T. M. 2004b: 'Reply to Ludlow’, in Zimmerman (2004), 37-46

Deasy, D. 2017: 'The triviality argument against presentism', Synthese (online first), https://doi.org/10.1007/s11229-017-1601-y

Deng, N. 2018: 'What is Temporal Ontology?', Philosophical Studies, 793-807 (online first)

Ingram, D. and Tallant, J. 2018: 'Presentism', The Stanford Encyclopedia of Philosophy (Spring 2018 Edition), Edward N. Zalta (ed.), URL = $<$ https://plato.stanford.edu/archives/spr2018/entries/presentism/>.

Lombard, L. B. 1999: 'On the Alleged Incompatibility of Presentism and Temporal Parts', Philosophia 27, 253-60

Lombard, L. B. 2010. 'Time for a Change: A Polemic Against the PresentismEternalism Debate', in Campbell, J. K., O’Rourke, M. and Silverstein, H. S. (eds.), Time and Identity, Cambridge/Mass.: MIT Press, 49-77

Ludlow, P. 2004: 'Presentism, Triviality, and the Varieties of Tensism', in Zimmerman (2004), 21-36

Meyer, U. 2005: ‘The Presentist’s Dilemma’, Philosophical Studies 122, 213-225

Meyer, U. 2013: 'The Triviality of Presentism', in Ciuni, R. et al. (eds.), New Papers on the Present: Focus on Presentism, Munich: Philosophia Verlag, 6787 
Miller, K. 2013: 'Presentism, Eternalism, and the Growing Block', in Dyke, H. and Bardon, A. (eds.), A Companion to the Philosophy of Time, Oxford: Blackwell, 345-64

Mozersky, M. J. 2011: 'Presentism', in Callender, C. (ed.), The Oxford Handbook of Philosophy of Time, Oxford: Oxford University Press, 122-44

Sider, T. 1999: 'Presentism and Ontological Commitment', The Journal of Philosophy 96, 325-47

Sider, T. 2006: ‘Quantifiers and Temporal Ontology’, Mind 115, 75-97

Stoneham, T. 2009: 'Time and Truth: The Presentism-Eternalism Debate', Philosophy 84, 201-18

Tallant, J. 2014: ‘Defining Existence Presentism’, Erkenntnis 79, 479-501

Thomasson, A. 1999: Fiction and Metaphysics, Cambridge: Cambridge University Press

Torrengo, G. 2012: 'Time and Simple Existence’, Metaphysica 13, 125-30

Williamson, T. 2013: Modal Logic as Metaphysics, Oxford: Oxford University Press.

Zimmerman, D. W. 1998: 'Temporary Intrinsics and Presentism', in van Inwagen, P. and Zimmerman, D. W. (eds.), Metaphysics: The Big Questions, Oxford: Blackwell, 206-19

Zimmerman, D. W. 2004: Oxford Studies in Metaphysics, Vol. 1, Oxford: Oxford University Press. 